\title{
Fecal Evacuation Disorder Among Patients With Solitary Rectal Ulcer Syndrome: A Case-control Study
}

\author{
Atul Sharma, Asha Misra and Uday C Ghoshal*
}

Department of Gastroenterology, Sanjay Gandhi Postgraduate Institute of Medical Sciences, Lucknow, India

\section{Background/Aims}

Data on frequency of fecal evacuation disorder (FED) among patients with solitary rectal ulcer syndrome (SRUS), hitherto an enigmatic condition, are scanty. Moreover, most such studies had limitations due to small sample size and lack of inclusion of healthy controls $(\mathrm{HC})$.

\section{Methods}

Forty patients with SRUS underwent symptom assessments, sigmoidoscopy, anorectal manometry, defecography, balloon expulsion test (BET); endoscopic ultrasound (EUS) of anal sphincter complex was performed in a subgroup. Physiological tests (anorectal manometry and BET) were also performed in $19 \mathrm{HC}$.

\section{Results}

Patients with SRUS (26/40 male, age 37 [18-80] years) more often had FED than HC (10/19 male, age 43 [25-72] years) as shown by weight needed to expel the balloon (300 [0-700] g vs. $100[0-400] \mathrm{g} ; P=0.006)$, a trend towards abnormal BET (need of $>200 \mathrm{~g}$ weight for expulsion) $(21 / 40$ [53\%] vs. 5/19 [26\%], $P=0.058)$ and impaired anal relaxation (14/40 [35\%] vs $2 / 19[10.5 \%] ; P=0.048$ ). Using Rome III criteria, most patients with SRUS reported having chronic constipation (36/40 [90\%]) in spite of having normal (Bristol stool type IV, 21/40 [53\%]) and diarrheal (types V, VI, VII, 6/40 [20\%]) stool forms (Asian classification). SRUS patients more often (17/40 [43\%]) had functional defecation disorder (Rome III criteria). Patients with SRUS with abnormal BET had thicker internal anal sphincter than those without (3.9 [3.4-7.0] mm vs $2.8[2.0-4.0] \mathrm{mm} ; P=0.01)$.

\section{Conclusions}

FED was commoner among patients with SRUS as evidenced by abnormal BET and sphincter relaxation. Those with abnormal BET had thicker internal sphincter on EUS than those without.

(J Neurogastroenterol Motil 2014;20:531-538)

\section{Key Words}

Constipation; Defecation; Dyschezia; Functional gastrointestinal disorders, anal sphincter

Received: March 12, 2014 Revised: June 28, 2014 Accepted: July 16, 2014

(c) This is an Open Access article distributed under the terms of the Creative Commons Attribution Non-Commercial License (http://creativecommons. org/licenses/by-nc/3.0) which permits unrestricted non-commercial use, distribution, and reproduction in any medium, provided the original work is properly cited.

*Correspondence: Uday C Ghoshal, MD, DNB, DM, FACG, RFF

Department of Gastroenterology, Sanjay Gandhi Post Graduate Institute of Medical Sciences, Lucknow 226014, India

Tel: +91-962-8842456, Fax: +91-522-2668017(or 2668078), E-mail: udayghosha@@gmail.com

Financial support: None.

Conflicts of interest: None.

Author contributions: Atul Sharma contributed to designing the study, study execution, data analysis and writing the paper; Asha Misra helped in performing the manometry and balloon expulsion test, data collection and analysis; Uday C Ghoshal contributed to designing and execution of the study, performed endoscopic ultrasound, contributed to data analysis and writing the paper. All authors read the final version of the paper and approved it.

ORCID: Uday C Ghoshal, http://orcid.org/0000-0003-0221-8495. 


\section{Introduction}

Solitary rectal ulcer syndrome (SRUS) is a disorder affecting all ages and presents with rectal bleeding, mucorrhea, tenesmus and feeling of incomplete evacuation. ${ }^{1}$ It may be considered as part of spectrum of diseases like anterior mucosal prolapse, solitary rectal ulcer (SRU) and full thickness rectal prolapse. ${ }^{2}$ Pathogenesis of SRUS is not known. Mucosal ischemia was proposed to be an etiological factor in the past. ${ }^{3}$ Recently, fecal evacuation disorder (FED; also known as functional defecation disorder) has been proposed to be an important factor in the pathogenesis of SRU in a few uncontrolled studies on small number of patients. ${ }^{4}$ Some studies showed symptomatic benefit, ulcer healing and improvement in mucosal blood flow following biofeedback in patients with SRUS. ${ }^{5-7}$

Accordingly we undertook a prospective case-control study to evaluate the frequency of fecal evacuation disorder among patients with SRUS compared to healthy control (HC) using anorectal manometry (ARM) and balloon expulsion test (BET). In a subgroup of patients, we also evaluated anal sphincter complex using endoscopic ultrasonography (EUS). In addition, clinical symptoms of patients with SRUS and defecography were also evaluated.

\section{Materials and Methods}

Forty patients with SRUS diagnosed by proctosigmoidoscopy and histopathology during a two and a half year period (from November 2011 to February 2014) were included. All patients underwent clinical evaluation, ARM, BET and defecography. In a subgroup of patients, we also evaluated anal sphincter complex using EUS. Patients who underwent anorectal surgery in the past or had associated inflammatory bowel diseases were excluded from the study.

Nineteen apparently healthy volunteers were included as controls. Healthy subjects also underwent clinical evaluation, ARM and BET. Defecography and EUS were not performed in this group. All the patients and controls consented to participate in the study. The Institutional Ethics Committee approved the study protocol.

\section{Clinical Evaluation}

Patients were evaluated clinically using a standard questionnaire including 8 categories of general gastrointestinal symp- toms (predominant stool form and frequency, bleeding per rectum, mucus discharge, tenesmus, feeling of incomplete evacuation, manual evacuation and straining while defecation). Predominant stool form (off laxative period) was recorded using Bristol stool form chart with pictorial representation and descriptor. ${ }^{8}$ The laxative consumption score per week (0: no laxatives, 1: high fiber diet \pm additional fiber supplement, 2 : oral laxatives, 3: enemas, polyethylene glycol electrolyte solution or rectal suppositories) was calculated. ${ }^{6}$

\section{Anorectal Manometry}

Each patient underwent ARM using a water perfusion manometry system (RMH, Melbourne, Australia) using a standard technique. ${ }^{9,10}$ A sixteen-lumen manometry catheter with balloon was used. The manometry catheter was inserted deep inside the rectum with the patient in the left lateral position. The catheter was subsequently pulled down slowly to be positioned at the high pressure zone of the sphincter with a few upper ports in the rectum and a few lower ports outside the anus. The lengths of the sphincter zone and resting sphincter pressure were estimated from an average of length and pressure data obtained. Subsequently the patient was asked to bear down and residual anal sphincter pressure was estimated. Rise in sphincter pressure on squeezing was measured. Subsequently, the balloon, mounted on the catheter tip positioned inside the rectum was inflated with an incremental volume of air (20, 40, $60 \mathrm{~mL}$ and so on). Recto-anal inhibitory reflex (RAIR) and rectal sensations (e.g., first feeling of distension, urge to pass stool and maximum tolerable limit) were also assessed during balloon inflation.

\section{Analysis of Manometry Signal}

The ARM signal was analyzed using Trace 1.2.1 software. The data were interpreted based on the standard criteria. ${ }^{10-14} \mathrm{~A}$ resting pressure of $>68 \mathrm{mmHg}$, squeeze pressure $>164$ and length of anal high pressure zone $>3.6 \mathrm{~cm}$ in females and $>4$ $\mathrm{cm}$ in males were considered as abnormal (high). Threshold volume for first sensation at $>20 \mathrm{~mL}$ in both gender, an urge to defecate at $>80 \mathrm{~mL}$ in male and $>60 \mathrm{~mL}$ in female and maximum tolerable volume of $>126 \mathrm{~mL}$ were taken as abnormal (high). Some of these cut-off values were based on a study from South Korea on 54 healthy subjects. ${ }^{15}$ The percentage of anal relaxation was calculated from the following equation. ${ }^{16}$

Anal resting pressure - anal residual pressure

Anal resting pressure 


\section{Balloon Expulsion Test}

A latex balloon, tied on the tip of a thin catheter was placed inside the rectum and filled with $60 \mathrm{~mL}$ water. The patient was asked to expel this while lying in left lateral position. If the balloon could be expelled without or with addition of weight of up to $200 \mathrm{~g}$ on the other end of the catheter, it was considered normal. ${ }^{17}$

\section{Defecography}

Defacography was performed after a cleansing rectal enema according to a standard technique. ${ }^{18,19}$ About $150-200 \mathrm{~mL}$ of thick barium paste was introduced inside the rectum. Lateral radiographs were obtained during rest, squeezing and defecation while the patient was sitting on a defecation chair. ${ }^{20}$

\section{Endoscopic Ultrasonography}

EUS was performed using a radial echoendoscope at 12 $\mathrm{MHz}$ frequency. Once the echoendoscope was inserted 3-4 cm inside the anal canal, the balloon mounted on its tip was inflated with water. Pubo-rectal sling was identified as a semicircular hy- per-echoic structure. On pulling the echoendoscope down, internal and external anal sphincters (IAS and EAS) were identified as hypo- and hyper-echoic circular structures (Figure E and F), respectively. Thickness of these muscles was measured. Thickness of IAS and EAS of greater than 3 and $9 \mathrm{~mm}$, respectively was considered abnormal. ${ }^{21-24}$

Functional defecation disorder was diagnosed according to the Rome III criteria if patient had chronic constipation and any 2 of the 3 physiological tests were abnormal; the test abnormalities included: (1) evidence of impaired evacuation, based on BET or imaging; (2) inappropriate contraction of pelvic floor muscles (i.e., anal sphincter or puborectalis) or less than $20 \%$ relaxation of basal resting sphincter pressure by manometry or imaging; or (3) inadequate propulsive forces assessed by manometry or imaging. ${ }^{25}$

\section{Statistical Methods}

Qualitative data were presented as proportion and the continuous data were presented as median (range). Categorical variables were analyzed using Chi-squared test and Fisher's exact test
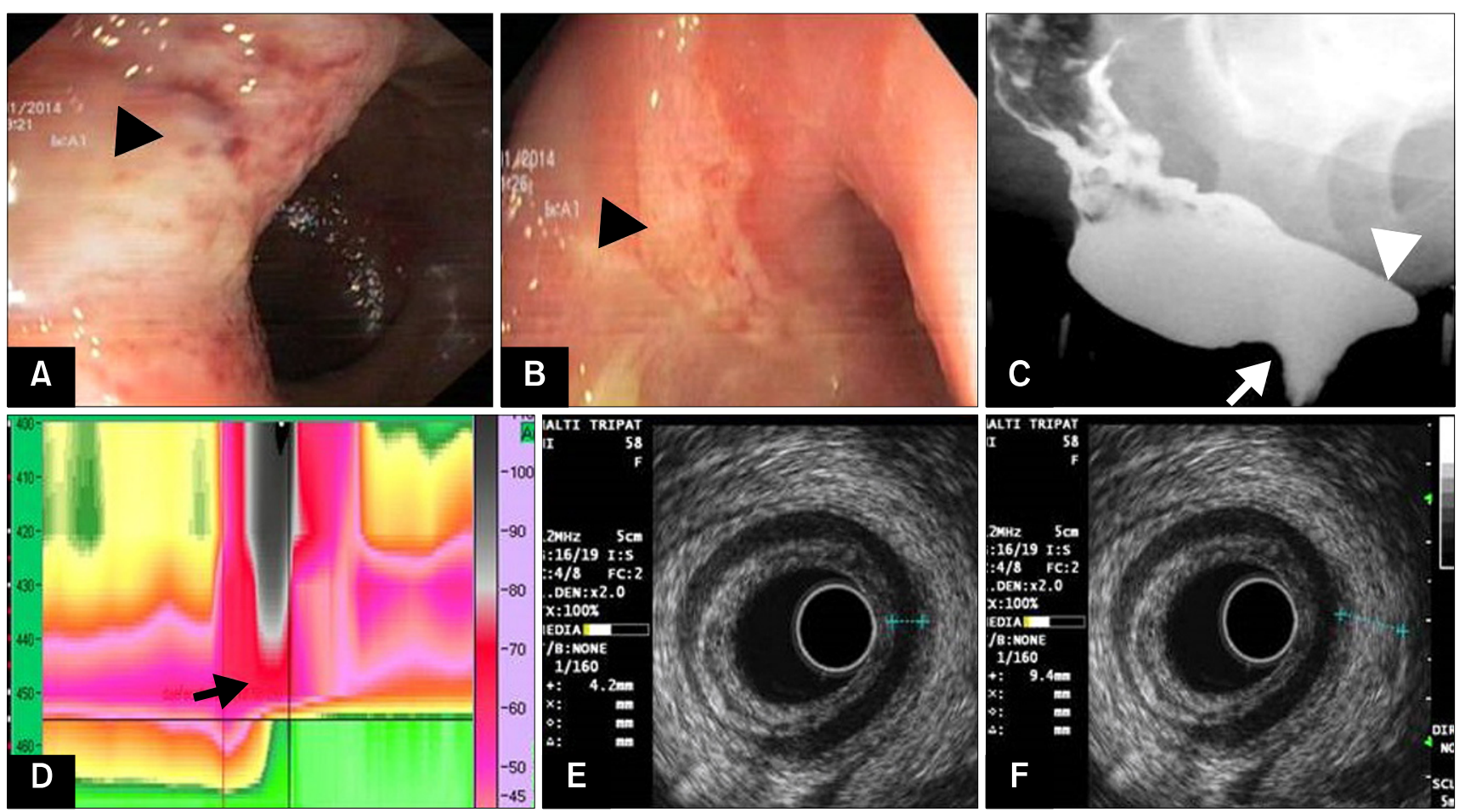

Figure. (A) 58-year-old female with solitary rectal ulcer syndrome on proctosigmoidoscopy (A and B, black arrow heads) and histology. Defecogram in this patient showed prominent puborectalis sling $(\mathrm{C}$, white arrow) and large anterior rectocele $(\mathrm{C}$, white arrow head). Anorectal manometry revealed lack of anal sphincter relaxation (D, black arrow) while defecation and even when rectal pressure was markedly increased. On endoscopic ultrasonography, internal and external anal sphincters were thick ( $\mathrm{E}$ and $\mathrm{F})$. 
Table 1. Bristol Stool Score and Endoscopic Finding With Solitary Rectal Ulcer Syndrome

\begin{tabular}{|c|c|c|}
\hline Type of Stool ${ }^{\mathrm{a}}$ & Bristol stool score & No. of patients $(\%)(\mathrm{n}=40)$ \\
\hline \multirow[t]{3}{*}{ Constipation } & Type 1 & $3(7)$ \\
\hline & Type 2 & $4(10)$ \\
\hline & Type 3 & $4(10)$ \\
\hline Normal & Type 4 & $21(53)$ \\
\hline \multirow{3}{*}{ Diarrhea } & Type 5 & $6(15)$ \\
\hline & Type 6 & $2(5)$ \\
\hline & Type 7 & $0(0)$ \\
\hline Endoscopic finding & & No. of patients $(\%)(n=40)$ \\
\hline \multirow[t]{5}{*}{ Rectal ulcer } & No rectal ulcer ${ }^{\mathrm{b}}$ & $10(25)$ \\
\hline & Solitary lesion & $23(57)$ \\
\hline & Two & $3(8)$ \\
\hline & Three & $2(5)$ \\
\hline & Multiple lesion & $2(5)$ \\
\hline \multirow[t]{5}{*}{ Size of rectal ulcer } & $<0.5 \mathrm{~cm}$ & $14(35)$ \\
\hline & $0.5-1 \mathrm{~cm}$ & $7(17.5)$ \\
\hline & $1-2 \mathrm{~cm}$ & $2(5)$ \\
\hline & $2-5 \mathrm{~cm}$ & $4(10)$ \\
\hline & $>5 \mathrm{~cm}$ & $3(7.5)$ \\
\hline \multirow[t]{3}{*}{ Hemorrhoids } & Gr I & $6(15)$ \\
\hline & Gr II & $3(7.5)$ \\
\hline & Gr III & $1(2.5)$ \\
\hline Laxative consumption score per week & No. of patients (\%) & No. with abnormal BET $(\%)^{\mathrm{c}}$ \\
\hline No laxative $(0)$ & $4(10)$ & $0 / 4(0)$ \\
\hline High fibre diet $+/-$ bran (1) & $10(25)$ & $5 / 10(50)$ \\
\hline Oral laxatives (2) & $24(60)$ & $16 / 24(67)$ \\
\hline Enemas, PEG or rectal suppositories (3) & $2(5)$ & $0 / 2(0)$ \\
\hline Total & $40(100)$ & $21 / 40(52.5)$ \\
\hline
\end{tabular}

${ }^{\mathrm{a}}$ Asian consensus on irritable bowel syndrome, ${ }^{37}$ b These patients had localized erythema/loss of vascular pattern with proven solitary rectal ulcer syndrome on histopathology, ${ }^{\mathrm{c}} \mathrm{P}=0.030$.

BET, balloon expulsion test; PEG, polyethylene glycol.

as applicable. Continuous data were analyzed using MannWhitney $\mathrm{U}$ test. $P$-values below 0.05 were considered significant. Data were analyzed by SPSS version 15 (SPSS, Inc., Chicago, IL, USA) and by R, Epicalc and R-studio software (R development core team, Vienna, Austria).

\section{Results}

\section{Demographic and Clinical Characteristics of Patients}

Patients with SRUS $(\mathrm{n}=40)$ were comparable with HC $(\mathrm{n}=19)$ in age $(37[18-80]$ vs. $43[25-72]$ years, $P=0.300)$ and gender (26/40 [65\%] male vs. $10 / 19$ [53\%] male, $P=0.300)$.

\section{Clinical Characteristics of Patients With Solitary Rectal Ulcer Syndrome}

All the 40 patients with SRUS had long standing symptoms (4 [range, 1-20] years). Common symptoms were mucus discharge per rectum $(\mathrm{n}=34,85 \%)$, feeling of incomplete evacuation $(\mathrm{n}=31,77 \%)$, bleeding per rectum $(\mathrm{n}=30,75 \%)$, straining $(n=28,70 \%)$, manual evacuation of stool $(n=27,68 \%)$ and tenesmus $(\mathrm{n}=11,27 \%)$. The stool patterns of patients with SRUS are presented in Table 1. They passed 21 (range, 1-56) stools per week. Most patients (36/40 [90\%]) had chronic constipation according to the Rome III criteria.

Table 1 summarizes the clinical characteristics of patients with SRUS with and without abnormal BET. Laxative consumption was noticed in $90 \%$ of patients. However patients with 
Table 2. Comparison of Anorectal Manometry and Balloon Expulsion Test Among Patients With Solitary Rectal Ulcer and Healthy Controls

\begin{tabular}{|c|c|c|c|}
\hline Parameters & SRUS $(n=40)$ & $\mathrm{HC}(\mathrm{n}=19)$ & $P$-value ${ }^{\mathrm{a}}$ \\
\hline Sphincter length $(\mathrm{cm})^{\mathrm{b}}$ & $2.5(1-4.5)$ & $2.5(1.5-3.5)$ & 0.730 \\
\hline Anal resting pressure $(\mathrm{mmHg})^{b}$ & $59.5(21-106)$ & $73(24-95)$ & 0.640 \\
\hline High resting pressure (n [\%]) & $17(42)$ & $10(52)$ & $0.460^{\mathrm{e}}$ \\
\hline Anal squeeze pressure $(\mathrm{mmHg})^{\mathrm{b}}$ & $120.5(42-248)$ & $103(60-195)$ & 0.200 \\
\hline High squeeze pressure (n [\%]) & $8(20)$ & $3(16)$ & $0.690^{\mathrm{e}}$ \\
\hline Anal residual pressure $(\mathrm{mmHg})^{\mathrm{b}}$ & $30.5(2-71)$ & $30(4-68)$ & 0.570 \\
\hline Rectal defecation pressure $(\mathrm{mmHg})^{\mathrm{b}}$ & $58.5(15-116)$ & $65(26-123)$ & 0.630 \\
\hline Balloon volume at first sensation $(\mathrm{mL})^{\mathrm{b}}$ & $40(20-120)$ & $40(10-100)$ & 0.960 \\
\hline High threshold for first sensation (n $[\%]$ ) & $29(72)$ & $11(58)$ & $0.260^{\mathrm{e}}$ \\
\hline Balloon volume at urge $(\mathrm{mL})^{\mathrm{b}}$ & $80(0-200)$ & $80(20-200)$ & 0.850 \\
\hline High threshold for urge sensation (n [\%]) & $23(57.5)$ & $9(47)$ & $0.460^{\mathrm{e}}$ \\
\hline Balloon volume at maximun tolerance $(\mathrm{mL})^{\mathrm{b}}$ & $220(80-400)$ & $200(70-400)$ & 0.460 \\
\hline High threshold for maximum tolerance (n $[\%]$ ) & $30(75)$ & $13(68)$ & $0.590^{\mathrm{e}}$ \\
\hline Balloon weight at expulsion $(g)^{\mathrm{b}}$ & $300(0-700)$ & $100(0-400)$ & 0.006 \\
\hline Abnormal BET $(\mathrm{n}[\%])^{\mathrm{c}}$ & $21(53)$ & $5(26)$ & $0.058^{\mathrm{e}}$ \\
\hline Percentage of anal relaxation & $38.2(0-96)$ & $48(0-94)$ & 0.150 \\
\hline Abnormal anal relaxation ${ }^{\mathrm{d}}$ & 14 & 2 & $0.048^{\mathrm{e}}$ \\
\hline
\end{tabular}

${ }^{\mathrm{a}}$ Mann-Whitney U test, ${ }^{\mathrm{b}}$ Median (range), ${ }^{\mathrm{c}}$ Abnormal balloon expulsion test defined as balloon explusion at weight greater than $200 \mathrm{~g}$, ${ }^{\mathrm{d}}$ Number of patients with $20 \%$ anal relaxation from baseline, ${ }^{\mathrm{e}} \mathrm{Chi}$-squared test.

SRUS, solitary rectal ulcer syndrome; HC, healthy controls.

abnormal BET more often reported consuming laxative than those without it $(21 / 21[100 \%]$ vs. $15 / 19$ [79\%], $P=0.030)$. All the other symptoms were comparable between the 2 groups.

\section{Findings at Proctosigmoidoscopy}

On proctosigmoidoscopy, the ulcerative lesions were solitary in $23(57 \%)$ and multiple in $7(18 \%)$ patients, respectively (Figure A and B). Ten (25\%) patients had focal area of hyperemia, loss of vascular pattern, nodulariy and polypoid lesions at a location typical of SRU (Table 1). On histopathology, features suggestive of SRU were found in all of them. Ten (25\%) patients had associated hemorrhoids.

\section{Comparison of Anorectal Manometry and Balloon Expulsion Test Among Patients With Solitary Rectal Ulcer and Healthy Control (see Table 2)}

The weight needed to expel the balloon was higher among patients with SRU compared to HC (300 [0-700] g vs. 100 $[0-400] \mathrm{g}, P=0.006)$. BET more often tended to be abnormal among patients with SRUS compared to HC (21 [53\%] vs. $5[26 \%], P=0.058)$. Impaired anal relaxation (Figure D) was more frequently detected among patients with SRUS than HC $(14 / 40$ [35\%] vs. $2 / 19$ [10.5\%], $P=0.040)$. All other ano-rectal manometry parameters were comparable among patients with SRU and HC (Table 2).

\section{Endoscopic Ultrasonography Parameters Among Patients With Solitary Rectal Ulcer With Normal and Abnormal Balloon Expulsion Test (see Figure)}

Sixteen patients with SRUS underwent anorectal EUS (8 with and other 8 without abnormal BET). IAS was thicker among patients with SRUS with abnormal BET as compared to those without $(3.9$ [3.4-7.0] $\mathrm{mm}$ vs. $2.8[2.0-4.0] \mathrm{mm}, P=$ 0.010 ) (Table 3).

\section{Defecography in Patients With Solitaly Rectal Ulcer Syndrome}

Twenty-two (55\%) patients with SRU had abnormal defecography. Anterior rectocele $(n=8)$ (Figure C), posterior rectocele $(\mathrm{n}=3)$, non-relaxing puborectalis $(\mathrm{n}=3)$, prolonged contrast retention $(n=5)$, rectal intussception $(n=2)$ and meg$\operatorname{arectum}(\mathrm{n}=1)$ were the abnormalities detected. 
Table 3. Comparison of Patients With Normal and Abnormal Balloon Expulsion Test Among Solitary Rectal Ulcer Syndrome Based on Endoscopic Ultrasound

\begin{tabular}{|c|c|c|c|}
\hline & \multicolumn{2}{|c|}{ Thickness on EUS (mm) } & \multirow[b]{2}{*}{$P$-value } \\
\hline & $\begin{array}{c}\text { Normal BET } \\
\quad(\mathrm{n}=8)\end{array}$ & $\begin{array}{l}\text { Abnormal BET } \\
\quad(\mathrm{n}=8)\end{array}$ & \\
\hline Internal anal Sphincter & $2.8(2.0-4.0)$ & $3.9(3.4-7.0)$ & 0.010 \\
\hline External anal Sphincter & $5.9(3.7-7.5)$ & $6.4(4.6-16.0)$ & 0.110 \\
\hline Puborectal sling & $7.2(4.8-9.1)$ & $10.0(4.7-23.0)$ & 0.500 \\
\hline
\end{tabular}

EUS, endoscopic ultrasound; BET, balloon expulsion test.

Data expressed as mean (range), ${ }^{a}$ Mann-Whitney $\mathrm{U}$ test.

\section{Evaluation for Functional Defecation Disorder in Patient With Solitary Rectal Ulcer Syndrome Using Rome III Criteria}

Seventeen of $40(42.5 \%)$ patients with SRUS fulfilled the Rome III criteria for functional defecation disorder (chronic constipation and abnormalities in 2 physiological test parameters). ${ }^{25}$

\section{Discussion}

The present study showed that, patients with SRUS (1) more often had chronic constipation by the Rome III criteria, (2) had FED as compared to $\mathrm{HC}$ as documented by BET and impaired anal relaxation, (3) more than half of patients with SRU had abnormal defecography, (4) about $40 \%$ of the patients with SRU had functional defecation disorders according to the Rome III criteria and (5) those with abnormal BET had thicker IAS than those without.

Pathogenesis of SRUS is largely unknown. Mucosal ischemia was proposed to be one of the mechanisms in the past. ${ }^{7}$ A few recent uncontrolled studies on small number of patients suggested a role of FED in the pathogenesis of SRUS. In an uncontrolled study from Netherlands, 5 of 19 patients who underwent defecography were found to have functional defecation disorder. ${ }^{26}$ In another uncontrolled observational study from Turkey, 9 of 34 patients with SRUS were found incontinent based on symptoms and had low anal resting and squeeze pressure on ARM. ${ }^{27}$ In a recent controlled study, FED was found to be commoner among 11 patients with SRU than 15 controls. Moreover, in this study, biofeedback retraining, which is used to correct FED, led to reduction in bleeding per rectum and healing of SRU. ${ }^{6,7}$ The present study, perhaps, is the largest case-control study showing that FED is associated with SRU.

Another interesting observation in the current study, which is documented perhaps for the first time in the literature, is thickening of IAS among patients with SRU and abnormal BET than those without. This is not entirely unexpected though there is no study in the literature to compare with. However, taking the analogy of achalasia cardia, which is a motility disorder of esophagus, thicker lower esophageal sphincter is associated with poorer esophageal emptying and poorer response to treatment. ${ }^{28-36}$

Interestingly, a large proportion of patients with SRU had constipation using the Rome III criteria and used laxatives in spite of passing type IV and even types V and VI stool; the latter types of stools are diagnostic of diarrhea according to the recent Asian consensus. ${ }^{37}$ Such discordance might be explained by the fact that in the presence of FED, it may be difficult to evacuate even the liquid stool due to functional obstruction of anorectal outlet. This finding, therefore not only supports the importance of functional anorectal obstruction in SRUS but also suggests that use of laxative or fiber supplement may not be very efficient in the management of constipation in patients with SRU and supports the role of biofeedback, which has been found to be useful in the management as reported in a recent study on a small number of patients. ${ }^{6}$ This observation also underscores the value of Asian criteria for diagnosis of constipation among patients with FED and SRUS.

The number of patients who reported mucus in their stool, digital evacuation and excessive straining were higher than those reported earlier. ${ }^{3}$ However, blood in stool was similar as described previously. ${ }^{3}$ Earlier, it has been suggested that rectal mucosal intussusception is a pathognomonic finding in patients with SRUS. ${ }^{38,39}$ In the present study, only 2 (5\%) of our patients showed mucosal intussusception and none had rectal prolapse as reported in other studies. ${ }^{6,40}$ Therefore, our study suggests that SRUS is not necessarily associated with rectal intussusception or prolapse.

One-fourth of our patients presented without rectal ulcer, another one-fifth had more than one ulcer and a few patients had rectal polyps. Thus, as described earlier, the term SRUS is a misnomer as ulcer is not always present and may not be solitary. ${ }^{4,41}$ Hemorrhoids were present in one-fourth of the patients, which can be explained by excessive straining during defecation. ${ }^{42}$

We found that a large proportion of patients with SRU had underlying FED and those with FED had thicker IAS. However, whether FED and increased IAS thickness are causes or effects of SRUS is not known. We believe that present study is important as it is the only prospective case-control study with a large sample size, which not only showed association of FED af- 
ter detail evaluation but also described for the first time the association of increased in IAS thickness and FED. We believe that further studies may be needed to correlate reversibility of thickness of IAS after biofeedback among those with abnormal BET with SRUS.

In conclusion, FED was more common among patients with SRUS as evidenced by abnormal BET and sphincter relaxation. Those with abnormal BET had thicker internal anal sphincter on EUS than those without.

\section{References}

1. Ertem D, Acar Y, Karaa EK, Pehlivanoglu E. A rare and often unrecognized cause of hematochezia and tenesmus in childhood: solitary rectal ulcer syndrome. Pediatrics 2002;110, e79.

2. Sun WM, Read NW, Donnelly TC, Bannister JJ, Shorthouse AJ. A common pathophysiology for full thickness rectal prolapse, anterior mucosal prolapse and solitary rectal ulcer. Br J Surg 1989;76:290295.

3. Vaizey CJ, van den Bogaerde JB, Emmanuel AV, Talbot IC, Nicholls RJ, Kamm MA. Solitary rectal ulcer syndrome. Br J Surg 1998;85: 1617-1623.

4. Sitzler PJ, Kamm MA, Nicholls RJ, McKee RF. Long-term clinical outcome of surgery for solitary rectal ulcer syndrome. Br J Surg 1998; 85:1246-1250

5. Rao SS, Patel RS. How useful are manometric tests of anorectal function in the management of defecation disorders? Am J Gastroenterol 1997;92:469-475.

6. Rao SS, Ozturk R, De Ocampo S, Stessman M. Pathophysiology and role of biofeedback therapy in solitary rectal ulcer syndrome. Am J Gastroenterol 2006;101:613-618.

7. Jarrett ME, Emmanuel AV, Vaizey CJ, Kamm MA. Behavioral therapy (biofeedback) for solitary rectal ulcer syndrome improves symptoms, mucosal bloodflow. Gut 2004;53:368-370.

8. Lewis SJ, Heaton KW. Stool form scale as a useful guide to intestinal transit time. Scand J Gastroenterol 1997;32:920-924.

9. Azpiroz F, Enck P, Whitehead WE. Anorectal functional testing: review of a collective experience. Am J Gastroenterol 2002;97:232240.

10. Jorge JM, Wexner SD. A practical guide to basic anorectal physiology investigations. Contemp Surg 1993;43:214-224.

11. Felt-Bersma RJ, Klinkenberg-Knol EC, Meuwissen SG. Anorectal function investigations in incontinent and continent patients. Differences and discriminatory value. Dis Colon Rectum 1990;33:479485; discussion 485-486.

12. Jorge JM, Wexner SD. Anorectal manometry: techniques and clinical applications. South Med J 1993;86:924-931.

13. Rao SS, Hatfield R, Soffer E, Rao S, Beaty J, Conklin JL. Manometric tests of anorectal function in healthy adults. Am J Gastroenterol 1999;94:773-783.

14. Ghoshal UC. Review of pathogenesis and management of constipation. Trop Gastroentrology 2007;28:91-95.

15. Lee HJ, Jung KW, Han S, et al. Normal values for high-resolution anorectal manometry/topography in a healthy Korean population and the effects of gender and body mass index. Neurogastroenterol Motil 2014;26:529-537.

16. Rao SS, Welcher KD, Pelsang RE. Effects of biofeedback therapy on anorectal function in obstructive defecation. Dig Dis Sci 1997;42: 2197-2205.

17. Pezim ME, Pemberton JH, Levin KE, Litchy WJ, Phillips SF. Parameters of anorectal and colonic motility in health and in severe constipation. Dis Colon Rectum 1993;36:484-491.

18. Halligan S, Nicholls RJ, Bartram CI. Evacuation proctography in patients with solitary rectal ulcer syndrome: anatomic abnormalities and frequency of impaired emptying and prolapse. AJR Am J Roentgenol 1995;164:91-95.

19. Mahieu P, Pringot J, Bodart P. Defecography: description of a new procedure and results in normal patients. Gastrointest Radiol 1984; 9:247-251.

20. Kim AY. How to interpret a functional or motility test - defecography. J Neurogastroenterol Motil 2011;17:416-420.

21. Nielsen MB. Endosonography of the anal sphincter muscles in healthy volunteers and in patients with defecation disorders. Acta Radiol Suppl 1998;416:1-21.

22. Falk PM, Blatchford GJ, Cali RL, Christensen MA, Thorson AG. Transanal ultrasound and manometry in the evaluation of fecal incontinence. Dis Colon Rectum 1994;37:468-472.

23. Sultan AH, Nicholls RJ, Kamm MA, Hudson CN, Beynon J, Bartram CI. Anal endosonography and correlation with in vitro and in vivo anatomy. Br J Surg 1993;80:508-511.

24. Papachrysostomou M, Pye SD, Wild SR, Smith AN. Anal endosonography in asymptomatic subjects. Scand J Gastroenterol 1993; 28:551-556

25. Appendix B: Rome III diagnostic criteria for functional gastrointestinal disorders. Am J Gastroenterol 2010;105:798-801.

26. Kuijpers HC, Schreve RH, ten Cate Hoedemakers H. Diagnosis of functional disorders of defecation causing the solitary rectal ulcer syndrome. Dis Colon Rectum 1986;29:126-129.

27. Simsek A, Yagci G, Gorgulu S, Zeybek N, Kaymakcioglu N, Sen D. Diagnostic features and treatment modalities in solitary rectal ulcer syndrome. Acta chir belg 2004;104:92-96.

28. Barthet M, Mambrini P, Audibert P, et al. Relationships between endosonographic appearance and clinical or manometric features in patients with achalasia. Eur J Gastroenterol Hepatol 1998;10:559-564.

29. Birk JW, Brand DL, Georgesson M, et al. The use of endoscopic ultrasound, manometrics and esophogram to evaluate pneumatic dilatation in the treatment of achalasia. Gastroenterology 1995;108:A59.

30. Devière J, Dunham F, Rickaert F, Bourgeois N, Cremer M. Endoscopic ultrasonography in achalasia. Gastroenterology 1989;96:12101213.

31. Bertolino JG, Mambrini P, Audibert P, et al. Endoscopic ultrasonography of the distal esophagus in achalasia. Gastroenterology 1995; 108:A59.

32. Posat $\mathrm{P}$, Chaussade $\mathrm{S}$, Palazzo L, et al. Endoscopic ultrasonography in achalasia. Gastroenterology 1990;98:253.

33. Miller LS, Liu JB, Barbarevech CA, et al. High-resolution endoluminal sonography in achalasia. Gastrointest Endosc 1995;42:545-549.

34. Trowers EA, Kimmey MB, Yee HC, Martin RW, Taniguchi D. Assessment of esophageal muscle thickness in achalasia using a high 
frequency linear endoscopic ultrasound probe. Gastrointest Endosc 1992;38:A244.

35. Hatlebakk JG, Odegaard S. Endoscopic ultrasound: a new look at achalasia? Eur J Gastroenterol Hepatol 1998;10:543-545.

36. Ghoshal UC, Rangan M. A review of factors predicting outcome of pneumatic dilation in patients with achalasia cardia. J Neurogastroenterol Motil 2011;17:9-13.

37. Gwee KA, Bak YT, Ghoshal UC, et al. Asian consensus on irritable bowel syndrome. J Gastroenterol Hepatol 2010;25:1189-1205.

38. Felt-Bersma RJ, Cuesta MA. Rectal prolapse, rectal intussusception, rectocele, and solitary rectal ulcer syndrome. Gastroenterol Clin
North Am 2001;30:199-222.

39. Halligan S, Nicholls RJ, Bartram CI. Proctographic changes after rectopexy for solitary rectal ulcer syndrome and preoperative predictive factors for a successful outcome. Br J Surg 1995;82:314-317.

40. Kang YS, Kamm MA, Nicholls RJ. Solitary rectal ulcer and complete rectal prolapse: one condition or two? Int J Colorectal Dis 1995;10:87-90.

41. Crespo Pérez L, Moreira Vicente V, Redondo Verge C, López San Román A, Milicua Salamero JM. "The three-lies disease": solitary rectal ulcer syndrome. Rev Esp Enferm Dig 2007;99:663-666.

42. Isenberg GA. Hemorrhoids. Clin Colon Rectal Surg 2011;24:5-13. 